\title{
Организация непрерывного образования в подготовке специалистов направления «Градостроительство»
}

\author{
Н.В.Данилина, НИУ МГСУ, Москва \\ Д.Н.Власов, ТиЦ Институт Генплана Москвы, НИУ МГСУ, Москва
}

В соответствии с мировыми тенденциями Национальный проект Российской Федерации «Образование» определяет формирование системы непрерывного образования как одну из основных стратегических задач развития для образовательныхучреждения высшей школы. В статье рассмотрены вопросы развития системы непрерывного образования по направлению подготовки «Градостроительство», которая включает три существующие ступени образования - бакалавриат, магистратуру и аспирантуру, а также предполагает наличие обширного портфеля программ дополнительного образования, который позволит постоянно совершенствовать свои навыки или осваивать новые компетенции.В статье предложена модель непрерывного образования, а также подход к организации системы непрерывного образования, основанные на интеграции существующей системы высшего образования, потребностей профессиональной отрасли и современных тенденций в развитии комфортной и безопасной городской среды. Определены основные виды и способы реализации программ дополнительного образования, которые будут входить в систему непрерывного образования. Апробация представленной модели представлена на образовательном процессе, организованном на кафедре «Градостроительство» НИУ МГСУ и включающем предложения по реализации дополнительной программы профессиональной переподготовки «Градостроительство». Программа разработана на базовой кафедре «Градостроительство» НИУ МГСУ и объединяет преподавательский состав кафедры и практикующих специалистов. Программа рассчитана на 350 часов обучения, организованного в дистанционной форме, и включает в себя 12 дисциплин, а также итоговую аттестационную работу. Предложенная программа переподготовки является одной из первых, разработанных в рамках развития дополнительного образования и интегрированных в систему непрерывного образования по направлению «Градостроительство».

Ключевые слова: непрерывное образование, переподготовка, повышение квалификации, градостроительство, программа дополнительного образования, Национальный проект «0бразование».

Organization of Continuous Education in the Training of Specialists in the Direction of "Urban Planning"

N.V.Danilina, NIU MGSU, Moscow

D.N.Vlasov, TEC Institute of the Moscow General Plan, NIU MGSU, Moscow

In accordance with global trends, the National project "Education" in the Russian Federation defines the formation of the Continuing Higher Education system as one of the main strategic development goals for higher education institutions. The article deals with the development of the system of continuing education in the field of urban planning training, which includes 3 existing stages of educationbachelor's, master's and postgraduate studies programs and also assumes the presence of an extensive portfolio of additional education programs that will allow to constantly improve your skills or develop new competencies. There are the specific model and approach to the organization of the Continuing Higher Education system in urban planning based on the integration of the existing system of higher education, the needs of the professional industry and current trends in the development of a comfortable and safe urban environment. There are the main types and methods of implementing additional education programs that will be the parts of proposed Continuing Higher Education system in urban planning. The implementation of the developed model is presented at the educational process organized at the Urban planning Department in National research Moscow State University of Civil Engineering, including proposals for the implementation of an additional education program of professional retraining in the field of urban planning. The program is developed on the Basic Urban planning Department and brings together teaching faculty and practicing professionals. The program is designed for 350 hours of distance learning and includes 12 disciplines, as well as final certification work. The proposed additional educational program is one of the first developed within the framework of Continuing Higher Education system in the field of urban planning.

Keywords: continuing education, retraining, advanced training, urban planning, additional education program, National project "Education".

\section{Актуальность}

В настоящее время мы живём в интенсивно изменяющемся мире: усложнение систем расселения, повышение плотности населения, формирование новых социальных коммуникаций в обществе, интенсификация мобильности, необходимость охраны природы, объектов культурного и исторического наследия, глобальные экологические, экономические, политические вызовы, стоящие перед городами и сельскими поселениями, - малая часть проблем, которые входят в об- 
ласть градостроительства. Они диктуют необходимость развития градостроительной деятельности за счёт расширения количества квалифицированных специалистов, способных принимать решения по устойчивому развитию урбанизированных территорий [1-3].

Актуальность и востребованность профессии «градостроитель» в России обоснована многочисленными федеральными, региональными, городскими программами, направленными на повышение связности, качества, комфортности, безопасности урбанизированной среды жизнедеятельности. Современные вызовы, которые стоят перед градостроителями, определяют необходимость развития системы непрерывного обновления квалификаций, которые позволят активно реагировать на любые изменения в градостроительной деятельности ${ }^{1}$.

Международный опыт подчёркивает необходимость развития системы непрерывного образования, которое даёт возможность специалистам совершенствовать свои компетенции или приобретать новые в течение всей профессиональной жизни. Такая система образования позволяет идти в ногу со временем, изучать современные тенденции и новые подходы без отрыва от работы. В области градостроительства особенно важным становится своевременное изучение новых технологий в условиях интенсивной цифровизации всех городских процессов, а также учёт глобальных вызовов, связанных с изменением климата, экологическими, природными и техногенными катастрофами, процессами миграции населения. Немаловажным является то, что по всему миру в настоящее время активно развиваются технологии дистанционного обуче-

${ }^{1}$ Кудрявцев А.П., Белоусов В.Н., Степанов А.В., Теличенко В.И., Есаулов Г.В., Андреев В.И. Современные проблемы архитектуры, градостроительства, строительства. Система непрерывного архитектурно-строительного образования в стране - гарантия качества жизнедеятельности // Отчет о НИР (Московский государственный строительный университет). - 2005. - 56 с.

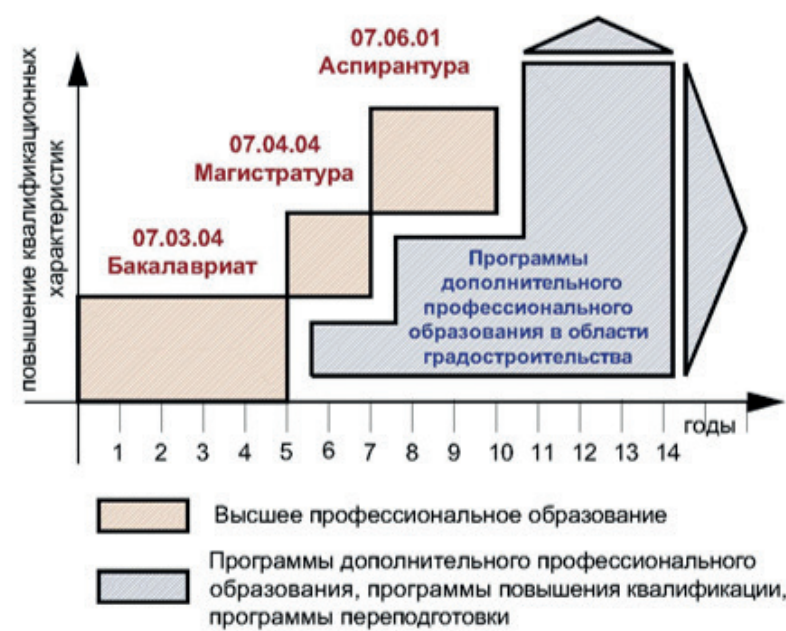

Рис. 1. Модель организации непрерывного образования по направлению подготовки «Градостроительство». Схема авторов статьи ния: образовательные платформы, порталы, программные комплексы, электронные библиотеки, - они позволяют значительно расширить географию и контингент обучающихся. Сложившиеся условия определяют стратегические направления развития российского образования [1-8].

Государственная программа Российской Федерации «Развитие образования» определяет реализацию процесса непрерывного образования как одну из стратегических задач программы развития образовательной деятельности, в том числе и по направлению подготовки «Градостроительство», для организаций высшего образования, которые обладают необходимыми материальными и трудовыми ресурсами для разработки и продвижения новых образовательных программ.

Целью статьи является разработка предложений и методики организации непрерывного образования по направлению подготовки «Градостроительство» для решения национальных задач повышения качества образования в области формирования комфортной и безопасной городской среды в каждом из регионов Российской Федерации, а также повышения конкурентоспособности российского образования на мировом рынке образовательных услуг.

Разработанная система должна включить в себя существующие направления подготовки в области градостроительства и расширить перечень знаний и компетенций, которые будут отвечать современным запросам человека, общества, страны к высокому качеству жизни в городах.

\section{Методы и материалы}

В настоящее время федеральные государственные образовательные программы определяют три ступени образования в области градостроительства:

07.03.04 - «Градостроительство»: бакалавриат -пять лет обучения;

07.04.04 - «Градостроительство»: магистратура, два года обучения;

07.06.01 - «Архитектура», профиль «Градостроительство»: аспирантура, три года обучения.

Требования организации непрерывного образования диктуют необходимость разработки программ, которые будут использоваться для дальнейшего повышения квалификации выпускников высшей школы.

На рисунке 1 предложена модель организации непрерывного образования, которая обеспечит возможность обучения и совершенствования профессиональных компетенций в течение любого периода профессиональной деятельности специалиста, работающего в сфере осуществления градостроительной деятельности.

Из представленной модели видно, насколько значительна ниша в системе непрерывного образования, которая должна быть занята программами дополнительного профессионального образования (ДП0). И это определяет перспективы его развития, разнообразие содержания и форм его реализации. 
Для заполнения этой ниши необходимо решение следующих двух задач.

- Формирование объёмного портфеля программ ДПо, покрывающего потребности всех целевых групп, имеющих высшее образование по направлению подготовки «Градостроительство», а также не имеющих его и желающих пройти программы переквалификации.

Рассмотрим основные формы реализации ДПо в области осуществления градостроительной деятельности:

- программы профессиональной переподготовки (не менее 250 часов), направленные на формирование профессиональных компетенций в области градостроительной деятельности. Такие программы должны включать только профессиональные дисциплины по направлению подготовки «Градостроительство» и быть реализованными высшими образовательными учреждениями, имеющими профессорско-преподавательский состав, соответствующий квалификационным требованиям, с привлечением практикующих специалистов отрасли;

- программы повышения квалификации (не менее 16 часов), направленные на расширение имеющихся профессиональных компетенций. Такие программы могут быть реализованы организациями, специализирующимися в теме программ ДП0, востребованных в отрасли.

- Развитие образовательной платформы для реализации портфеля ДПО в дистанционной форме с целью обеспечения доступа к нему всех целевых групп вне зависимости от места проживания.

В настоящее время существует два вида образовательных платформ для реализации дистанционного обучения:

- открытые платформы, на которых пользователь имеет возможность выбирать программы ДПО в онлайн режиме как бесплатные с открытым доступом (open source: Moodle, Coursera, E-learning, и.т.п.), так и с платным доступом (iSpring, Antitreningi.ru, и.т.п.). На таких платформах имеется широкий выбор программ ДПО со всего мира и, соответственно, большее количество пользователей;

- закрытые платформы, доступ к которым открывается только после оплаты программы ДПО. На таких платформах осуществляется обучение ограниченного контингента по ограниченному количеству программ. Такие платформы используются только как инструмент реализации программ ДП0, но не их распространения, что является их недостатком.

Современный уровень развития градостроительства в России, а также задачи, которые стоят в области развития градостроительного образования, позволяют выделить несколько направлений разработки программ ДП0, которые могут быть востребованы на рынке образовательных услуг:

1) программы профессиональной подготовки, направленные на приобретение основных знаний, умений и навыков градостроительной деятельности. Востребованность подобных программ обусловлена тем, что выпуск дипломи- рованных специалистов-градостроителей начался не более десяти лет назад. Как следствие, в профильных организациях существует недостаток кадров, обладающих профильным образованием. Особенно данная проблема актуальна для самих образовательных организаций, для которых ФГОС предъявляет строгие требования к профильной квалификации преподавателей, а также для государственных предприятий, к сотрудникам которых также предъявляются строгие квалификационные требования. Данные программы должны быть основаны на содержании аккредитованных программ бакалавриата и магистратуры по направлению «Градостроительство» и обеспечивать освоение компетенций, которые соответствуют профессиональному стандарту 10.006 «Градостроитель»;

2) программы повышения квалификации, которые обеспечивают единичные компетенции в определённой области знаний. Они предназначены для совершенствования навыков у профессионально специализирующихся в конкретной области градостроительства и направлены на углубление знаний в соответствии с современными тенденциями развития отрасли. Наиболее перспективными направлениями являются:

- современные технологии в градостроительстве: 3D-моделирование городской среды и процессов, создание информационных моделей, параметрическое проектирований, ВIM- и СІМ-технологии и т.п.;

- глобальные проблемы устойчивого развития городов: изменение климата, последствия процессов урбанизации, миграции населения, управление рисками от природных и техногенных катастроф;

- проблемы «зелёной» повестки дня: обеспечение экологической безопасности городской среды, ресурсосбережение и энергоэффективность городских решений, инженерное обеспечение территорий;

- городская политика, организация системы управления градостроительной деятельностью, вопросы разработки градостроительной документации, публичные слушания и вовлечение населения;

- транспортное планирование и проектирование: управление доступом к улично-дорожной сети, изменение мобильности населения, организация движения беспилотных транспортных средств, интермодальные системы пассажирского транспорта, подходы к планированию территорий с ограничением использования автомобилей, управление парковочными пространствами.

- охрана культурного и исторического наследия, определение границ и статуса исторических поселений и объектов, реконструкция, реновация, джентрификация территорий с учётом охраны культурного и исторического наследия.

В настоящее время Россия находится в начале пути развития непрерывного образования, в том числе и в области градостроительства. В целом эта задача ложится на профильные и отраслевые высшие образовательные учреждения, 
которые обладают необходимыми материально-техническими и кадровыми ресурсами.

\section{Внедрение}

Предложенная модель непрерывного образования по направлению подготовки «Градостроительство» в настоящее время внедряется в Московском научно-исследовательском государственном строительном университете (НИУ МГСУ) на кафедре «Градостроительство» совместно с базовой кафедрой «Градостроительство», организованной совместно с ГАУ «Институт Генплана Москвы».

Кафедра «Градостроительство» осуществляет подготовку специалистов всех уровней высшего образования: бакалавров, магистров, аспирантов - всего порядка 380-и обучающихся. Организация непрерывного образования является одной их стратегических целей развития образовательной деятельности, в задачи которой входит формирование портфеля программ ДПО.

С 2019 года на кафедре разработана и реализуется очная программа ДПо «Градостроительство», преподавание

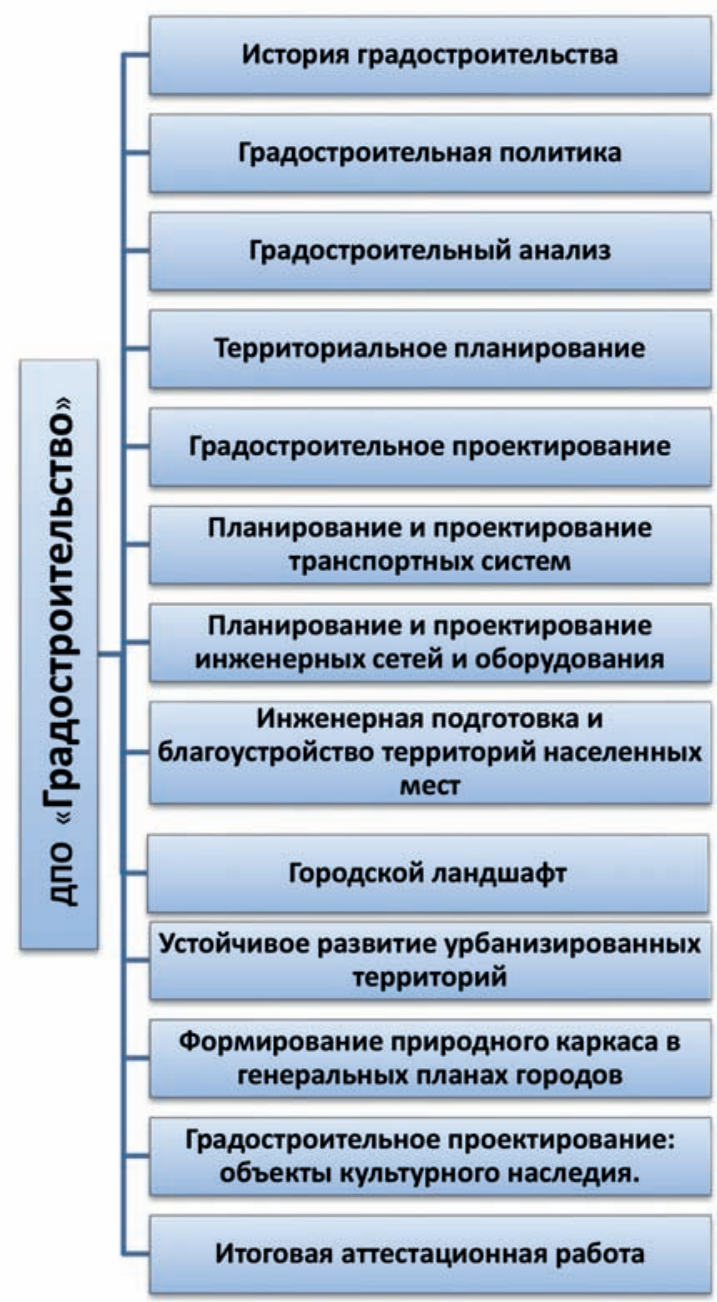

Рис. 2. Структура программы профессиональной переподготовки ДПО «Градостроительство» на 350 часов. Схема авторов статьи которой с 2020 года будет осуществляться в дистанционной форме. На рисунке 2 представлена структура программы ДП0 «Градостроительство» объёмом 350 часов, прошедшая профессионально-общественную аккредитацию. В состав программы входят основные дисциплины из курса бакалавриата, что позволяет обеспечить слушателя основными профессиональными компетенциями в области осуществления градостроительной деятельности.

Целевой группой слушателей являются специалисты, работающие в области осуществления градостроительной деятельности, которые не имеют профильного образования или им требуется повышение квалификации в соответствии с современными тенденциями. Они получают возможность в дистанционной форме приобрести знания в области ведения градостроительной деятельности.

Цель программы направлена на получение и углубление профессиональных компетенций в области ведения градостроительной деятельности. Программа объединяет отечественный и международный опыт, накопленный в НИУ МГСУ, практический опыт базовой кафедры «Градостроительство», а также изучение лучших практик градостроительства, реализуемых в настоящее время в мире, которые обеспечивают достижение стратегической цели - устойчивое развитие городских территорий, и направлены на рассмотрение задач формирования комфортной и безопасной городской среды, решение вопросов охраны природы и территорий, обладающих признаками культурно-исторического наследия, транспортных и инженерных проблем городов и регионов. Предлагается рассмотрение кросс-дисциплинарных задач в области обеспечения качества городской среды, удовлетворения потребностей всех групп населения, сохранения культурной идентичности, вовлечения населения в процесс ее развития.

Программа ДП0 «Градостроительство» предлагает следующие возможности для слушателей.

- Преподавание дисциплин ведётся штатными сотрудниками кафедры Градостроительство» НИУ МГСУ, профессиональная квалификация которых соответствует требованиям ФГОС 3++: доктора и кандидаты технических наук, архитектуры по научной специальности «Градостроительство», обладающие теоретическим и практическим опытом работы.

- Для практико-ориентированного обучения предусмотрена организация очных мастер-классов от ведущих специалистов отрасли, обладающих специализированными профессиональными компетенциями, с возможностью трансляции для обучающихся, которые не могут присутствовать лично.

- Организация доступа слушателей к образовательному порталу, записям лекционных материалов, другим учебным материалам и электронной библиотеке в целом.

- Самостоятельная работа слушателей направлена на расширение круга знаний и выполнение практических проектов, в том числе в области осуществления градостроительной деятельности на своём предприятии. 
Представленная программа ДПО - один из первых этапов в развитии непрерывного образования в области осуществления градостроительной деятельности, который положит начало переходу градостроительного образования на новый качественный уровень и повысит его конкурентоспособность на мировом рынке образовательных услуг.

\section{Результаты}

- Развитие непрерывного образования в области градостроительства, которое входит в Национальный проект «0бразование» и Стратегическое направление «ЖКХ и городская среда», относится к приоритетным направлениям обновления навыков и приобретения компетенций специалистами, осуществляющими профессиональную градостроительную деятельность.

- НИУ МГСУ, являющийся ведущим вузом страны в области строительства и архитектуры, представляет собой идеальную образовательную площадку для развития системы непрерывного образования в области градостроительства и обладает необходимыми компетентными кадрами для реализации образовательной деятельности по направлению подготовки «Градостроительство». Обучение в отраслевом вузе позволяет оперативно повышать профессиональную квалификацию в соответствии с постоянно меняющимися внешними требованиями градостроительной отрасли и внутренними потребностями организации.

- Программа ДПО «Градостроительство», объединяющая опыт научно-педагогических работников НИУ МГСУ и ведущих представителей работодателя отрасли, предлагает возможности получения или расширения профессиональных компетенций в области градостроительного планирования, проектирования, а также ведения исследовательской деятельности в области градостроительства.

\section{Литература}

1. Данилина, Н.В. Устойчивое развитие умных городов: образовательная деятельность в области градостроительства / Н.В. Данилина // Биосферная совместимость: человек, регион, технологии. - 2019. - № 3 (27). - С. 38 - 43

2. Ivanova Z.I. Digital education as a prerequisite for improving the institution of public hearings / Z.I. Ivanova, N.V Danilina, M.A. Slepnev // International Journal of Applied Exercise Physiology. - 2019. - Vol. 8., № 2.1. - P. 1003-1009. D0I: $10.30472 /$ ijaep.v8i2.1.566

3. Щербина, E.B. Научно-методические основы построения модуля «проектирование устойчивой городской среды» В процессе обучения бакалавров и магистров по направлению «Градостроительство» / Е.В. Щербина, Н.В. Данилина, А.С. Маршалкович // Экология урбанизированных территорий. - 2015. - № 1. - C. 70-74.

4. Aguaded-Ramírez E. Smart City and Intercultural Education / E. Aguaded-Ramírez // Procedia - Social and Behavioral Sciences. - 23721. - 2017. cc. 326-333.
5. Silva Vieira M.M., Aguiar Neto B. G. Peer. Instruction: Continuing Teacher Education in Higher Education // Procedia Social and Behavioral Sciences. - 2016. - Vol. 2175. - P. 249-256.

6. Shweta Mishra. Social networks, social capital, social support and academic success in higher education: A systematic review with a special focus on 'underrepresented' students / Shweta Mishra // Educational Research Review. - 2020. - Vol. 29. - 100307.

7. Urban poverty and education. A systematic literature review / Marisol Silva-Laya, Natalia D'Angelo, Elda García [et al.] // Educational Research Review. - 2020. - Vol. 29. -100280.

8. Urban sustainability education: Challenges and pedagogical experiments / Nan Li, Deland Chan, Quan Mao [et al.] // Habitat International. - 2018. - Vol. 71. - P. 70-80.

\section{References}

1. Danilina N.V. Ustoichivoe razvitie umnykh gorodov: obrazovatel'naya deyatel'nost' v oblasti gradostroitel'stva [Sustainable development of smart cities: educational activities in the field of urban planning]. In: Biosfernaya sovmestimost': chelovek, region, tekhnologii [Biosphere compatibility: man, region, technology], 2019, no. 3 (27), pp. 38-43.

2. Ivanova Z.I. Danilina N.V, Slepnev. M.A. Digital education as a prerequisite for improving the institution of public hearings. In: International Journal of Applied Exercise Physiology, 2019, vol. 8, no. 2.1, pp. 1003-1009. D0I: 10.30472/ ijaep.v8i2.1.566. (in Engl.)

3. Shcherbina E.V., Danilina N.V., Marshalkovich A.S. Nauchnometodicheskie osnovy postroeniya modulya «proektirovanie ustoichivoi gorodskoi sredy» v protsesse obucheniya bakalavrov i magistrov po napravleniyu «Gradostroitel'stvo» [Scientific and methodological foundations for building the module "designing a sustainable urban environment" in the process of teaching bachelors and masters in the direction of "Urban planning"]. In: Ekologiya urbanizirovannykh territorii [Ecology of urbanized territories], 2015, no. 1, pp. 70-74 (In Russ., abstr.in Engl.)

4. Aguaded-Ramírez E. Smart City and Intercultural Education. Procedia - Social and Behavioral Sciences, 2017, Vol. 23721, pp. 326-333 (in Engl.)

5. Marili M. da Silva Vieira, Benedito Guimarães Aguiar Neto Peer Instruction: Continuing Teacher Education in Higher Education. Procedia - Social and Behavioral Sciences, 2016, Vol. 2175, pp. 249-256 (In Engl.)

6. Shweta Mishra. Social networks, social capital, social support and academic success in higher education: A systematic review with a special focus on 'underrepresented' students. In: Educational Research Review, 2020, Vol. 29, 100307.

7. Marisol Silva-Laya, Natalia D'Angelo, Elda García, Laura Zúñiga, Teresa Fernández. Urban poverty and education. A systematicliterature review. In: Educational Research Review, 2020, Vol. 29, 100280 (In Engl.)

8. Nan Li, Deland Chan, Quan Mao, Kevin Hsu, Zhiyong Fu. Urban sustainability education: Challenges and pedagogical experiments. In: Habitat International, 2018, Vol. 71, pp. 70-80. (In Engl.) 
Данилина Нина Васильевна (Москва). Доктор технических наук. Заведующая кафедрой «Градостроительство» ФГБОУ В0 «Национальный исследовательский Московский государственный строительный университет» (129337, Москва, Ярославское шоссе, 26. НИУ МГСУ). Эл. почта: DanilinaNV@mgsu.ru.

Власов Денис Николаевич (Москва). Доктор технических наук, советник РААСН. Заместитель руководителя Транспортноинженерного центра Института Генплана Москвы, профессор кафедры «Градостроительство» ФГБОУ ВО «Национальный исследовательский Московский государственный строительный университет» (129337, Москва, Ярославское шоссе, 26. НИУ мГСУ). Эл. почта: VlasovDN@mgsu.ru.

Danilina Nina V. (Moscow). Doctor of Technical Sciences. Head of the Urban Planning Department at the National Research Moscow State University of Civil Engineering (26 Yaroslavskoye Highway, Moscow, 129337. MGSU). E-mail: DanilinaNV@mgsu.ru.

Vlasov Denis N. (Moscow). Doctor of Technical Sciences, Advisor to RAACS. Deputy Head of the Transport and Engineering Center of the The Moscow General Planning Research and Project Institute, Professor of the Urban Planning Department at the National Research Moscow State University of Civil Engineering (26 Yaroslavskoye Highway, Moscow, 129337. MGSU). E-mail: VlasovDN@ mgsu.ru. 